\title{
Redescription of the genus Megastilicus Casey (Staphylinidae, Paederinae) with the description of a new species
}

\author{
Dagmara ŻYŁA ${ }^{1, *}$ \& Katarzyna KOSZELA ${ }^{2}$ \\ ${ }^{1}$ Department of Invertebrate Zoology and Parasitology, \\ University of Gdańsk, 80-308, Gdańsk, Poland. \\ ${ }^{1}$ Department of Ecology, Evolution and Organismal Biology, \\ Iowa State University, Ames, IA 50011, USA. \\ ${ }^{1,2}$ Museum and Institute of Zoology, Polish Academy of Sciences, \\ Wilcza 64, 00-679, Warszawa, Poland. \\ ${ }^{*}$ Corresponding author: zyladagmara@gmail.com \\ 2Email: kat.koszela@gmail.com \\ ${ }^{1}$ urn:1sid:zoobank.org:author:0A7FEB0F-308C-4FDF-AD0D-8074BC69F0B3 \\ ${ }^{2}$ urn:1sid:zoobank.org:author:06C16202-4569-4156-9FB1-EA4DEE14AE88
}

\begin{abstract}
The myrmecophilous Paederinae rove beetle genus Megastilicus Casey, 1889 from North America is reviewed based on museum specimens. Prior to this study, the genus was monotypic with one species Megastilicus formicarius Casey, 1889 described. Here, we provide a redescription of the genus and the type species, designate a lectotype, and provide pictures of habitus and illustrations of the aedeagus and genital segments. Additionally, we describe a new species for the genus, Megastilicus iowaensis sp. nov., include an identification key to the two species and present the distribution map of both of them, including new state records. We discuss the assignment of the genus to the subtribe Stilicina based on morphological features.
\end{abstract}

Keywords. Coleoptera, Paederinae, new species, myrmecophily, taxonomy.

Żyła D. \& Koszela K. 2021. Redescription of the genus Megastilicus Casey (Staphylinidae, Paederinae) with the description of a new species. European Journal of Taxonomy 778: 138-147.

https://doi.org/10.5852/ejt.2021.778.1575

\section{Introduction}

Beetles of the genus Megastilicus Casey, 1889 are ant nest predators found with Formica ulkei Emery, 1893, F. subsericea Say, 1836 and F. exsectoides Forel, 1886 in Northeast and Midwest USA and Central-East Canada. The genus was first described by Casey in 1889 to accommodate a single species Megastilicus formicarius Casey, 1889. In his revision of North American Paederini Fleming, 1821, Casey (1905) assigned the genus to a subtribe Stilicina Casey, 1905 (referred there as Stilici), incorporated it into the key to genera of the subtribe and expanded the description of the species. Moore \& Legner (1974) in their key to the Staphylinidae Latreille, 1802 of America north of Mexico provided a more detailed description and a drawing of the habitus. The genus was also included in Newton et al. (2000) key of American beetles in a couplet with Eustilicus Sharp, 1886. 
It was already mentioned in the original description (Casey 1889) that the genus is myrmecophilous and perhaps a predator (Wickham 1900), but its biology and behaviour was studied in more detail by Park (1935). His studies revealed several defence mechanisms that allow the beetle to enter the nest and prey on the host. Such mechanisms are, e.g., their hard exoskeleton, the overall agility and a defensive abdominal secretion released when they are attacked by an ant. He also noted that the beetle is clearly not integrated into the nest and persecuted by its hosts (Park 1935). The genus was also mentioned in a summary of myrmecophilous rove beetles by Parker (2016).

Megastilicus is an example of a genus that has never been the subject of a modern revision, lacking a proper illustration of habitus and genital structures. This motivated us to make a redescription of the genus, and while studying multiple specimens, we additionally discovered a new species that we here describe.

\section{Material and methods}

\section{Specimen preparation and photographs}

Specimens were relaxed in warm water and dissected. Specimens were studied using a Nikon SMZ1500 and an Olympus SZX9 stereo microscopes. All measurements are given in millimetres and were made with an ocular micrometer mounted on a stereoscopic microscope. A Nikon DS-Fil camera was used for taking pictures of habitus, and photos were stacked using Zerene Stacker software by the PMax method (ver. 1.04, Zerene Systems LLC). The pictures were further edited in Adobe Photoshop CS6 while illustrations were made in Adobe Illustrator CS6 (ver. 13.0, Adobe Systems Inc.) based on photographs. The distribution map was drawn in SimpleMappr (Shorthouse 2010) and modified in Adobe Photoshop CS6. Morphological terminology follows Bogri et al. (2020). Data from the specimen labels are cited verbatim (with original spelling retained) and are provided inside quotation marks (" "). The slash (/) separates labels in each specimen. Ant species given in square brackets were identified by the first author (DŻ), using the Key to New England Formica (AntWiki 2017). Identifiers of the ant species named on original specimen labels are unknown.

\section{Specimen repositories}

Material from the following collections was used in the current study and is currently deposited there:

MCZ = Museum of Comparative Zoology, Harvard University, Cambridge, Massachusetts, USA (Crystal Maier)

$\mathrm{NMNH}=$ National Museum of Natural History, Smithsonian Institution (former USNM), Washington, District of Columbia, USA (late Terry Erwin, Charyn Micheli, Floyd Shockley)

$\mathrm{AMNH}=$ American Museum of Natural History, New York City, New York, USA (Lee Herman)

\section{Results}

\section{Taxonomy}

Class Insecta Linnaeus, 1758

Order Coleoptera Linnaeus, 1758

Family Staphylinidae Latreille, 1802

Subfamily Paederinae Fleming, 1821

Tribe Lathrobiini Laporte, 1835

Subtribe Stilicina Casey, 1905

Genus Megastilicus Casey, 1889

Figs 1-2 
Megastilicus Casey, 1889: 183 (original description).

Megastilicus - Casey 1905: 227 (description and key). — Wickham 1900: 3 (note); 1911: 15 (checklist). — Leng \& Wickham 1920: 24 (catalogue). — Holmquist 1928a: 84 (note); 1928b: 335 (note). Park 1929: 199 (record/note); 1935: 217 (biology). — Blackwelder 1939: 100, 119 (key and list). — Herman 1970: 3 (note). — Moore \& Legner 1979: 107-108 (description and drawing). — Newton et al. 2020: 327, 387 (key and note). — Bousquet et al. 2013: DwC-A database (checklist). — Parker 2016: 78 (note).

\section{Type species}

Megastilicus formicarius Casey, 1889.

\section{Diagnosis}

Body robust, antennae short and stout. Body covered with short, black, stout setae. Dorsal surface of head, pronotum and elytra granulate. Head orbicular in shape.

\section{Redescription}

BoDy. Medium size beetle; body robust, somewhat flattened. Colour of specimens from pale brown/sandy to brown/reddish brown. Head, pronotum and elytra covered with short, black setae. Dorsal surface of body densely granulato-reticulate, abdomen smoother, and not granulate.

HEAD. Orbicular, with rounded hind angles; widest in middle, tapering towards antennal insertions anteriorly and towards neck posteriorly; disc of head without punctation, with leather-like integument. Head wider and longer than pronotum. Antennae short, reaching only to anterior part of pronotum, compact, mostly transverse, with well-developed stems in between, pubescent. Labrum large, almost completely covering mandibles from above, notched, broadly emarginate in middle at apex, with two distinct lobes, each bearing long and pale macroseta and comb of setae near emargination; emargination bidentate; weakly sclerotised, connected with head by membrane. Mandibulae without prostheca, with two teeth on right and one on left mandibula. Maxillary palpomere 3 about twice as long as palpomere 2; palpomere 4 elongate and thin, around $1 / 3$ of palpomere 3 length and $1 / 3$ of palpomere 3 width. Labial palpomere 1 shorter and thinner than palpomere 2 ; palpomere 2 slightly elongate, expanded toward apex, twice as long as palpomere 1; palpomere 3 thin and long, longer than half of palpomere 2 and $1 / 4$ of palpomere 2 width. Mentum transverse. Submentum with pair of setae on sides. Ligula bilobed. Gular sutures fused. Eyes small, from $1 / 5$ to $1 / 6$ of head length. Temples long, more than half of head length. Shallow longitudinal depression on each side of head ventrally. Neck distinct and narrow, about $1 / 5$ of head width.

Thorax. Pronotum longer than wide, anterior angles obtuse, widest in middle. Superior marginal line deflexed, becoming indistinct close to apical portion of prosternum, but reaching prosternum. Basisternum without macrosetae or microsculpture, but surface wrinkled. Furcasternum triangular, acute. Pronotal disc dull, with leather-like integument, without punctures. Elytra longer and wider than pronotum, without punctures, without epipleural ridge; humeral angles indistinct, rounded; surface dull with leather-like integument, with unorganised rows of small, black macrosetae. Anterior margin of scutellum rounded. Posterior (?) scutellar ridge present. Hind wings fully developed.

LEGS. Long and slender, uniformly covered with glossy black macrosetae. All tarsi 5-segmented. Tarsomeres 1-4 of protarsus not inflated. Protibia with three fully developed protibial combs. One pair of empodial setae on each tarsus, equal to or slightly shorter than claws (never shorter than half of claw length). Meso and metatarsomere 1 longer than 2. Metatarsi almost as long as metatibiae, with tarsomeres 1-4 decreasing gradually in length, metarsomere 1 shorter than 2 and 3 combined, slightly longer than tarsomere 5 . 
AbDomen. Sternite III with medial longitudinal keel. Abdomen widest at tergite V. Abdominal segments III to VII with pair of paratergites on each side; setae along length of abdomen. Tergite/sternite IX or X with dense setation. [Similar structure for female.]

AEDEAGus. With parameres reduced and fused to median lobe; ventral process slightly longer than uneverted internal sac; in parameral view with apex of ventral process acute, sides sinuate; dorsal plate rather large and relatively weakly sclerotised (Figs 1D-E, 2D-E).

\section{Megastilicus formicarius Casey, 1889}

Fig. 1

\section{Type material}

Lectotype (here designated)

USA • ${ }^{\uparrow}$; “Drac. Mass. / Type USNM 38356 / Megastilus formicarius Csy"; NMNH.

\section{Paralectotypes}

USA • 1 spec.; "Drac. Mass. / Casey bequest 1925 / formicarius-5 PARATYPE USNM 38356"; NMNH - 1 spec.; "Casey bequest 1925 / formicarius-2 PARATYPE USNM 38356"; NMNH • 1 spec. with ant; "Casey bequest 1925 / formicarius-3 PARATYPE USNM 38356"; NMNH • 1 ภे; "Mass / Casey bequest 1925 / formicarius-6 PARATYPE USNM 38356"; NMNH.

\section{Additional studied material}

USA • 1 spec.; "Pen Mar Pa"; NMNH • 1 spec.; "Harrisonville Mo. / Aug 2015"; NMNH • 1 spec.; "Cumberland Co. / Maine 1916"; NMNH • 1 spec.; "Newark NJ"; NMNH • 1 spec.; "Linell? Coll Chittenden"; NMNH 1 ô; "CypMills Tex / Coll Chittenden"; NMNH 1 spec.; "Sherborn, Massachusetts / IV-5'-25 / C.A. Frost/John George Gehring collection"; MCZ • 1 spec. [with Formica exsectoides]; "Wickham collection 1933 / Iowa City / Wickham IV-24-98"; MCZ • 2 specs; "Natick / V-12-12 / Mass"; MCZ $\bullet 9$ specs; "Drac. Mass / 4/4/-86"; MCZ 1 spec. [with Formica exsectoides]; "Newfoundl'd, N.J. / X.17.1913 / C.A. Frost / C.A. Frost Collection 1962"; MCZ • 1 spec.; "Chocorua N.H. / 5-2-06 / F.C. Bowditch Collection"; MCZ • 1 spec.; "Palos Park / Ill. / 4.14.34 / c. Seevers"; AMNH • 1 spec.; "Natik Mass. Frost. 12.5 / Massachusetts / N.am / Mus 8 crm"; AMNH • 1 spec.; "Crawfordsville Ind. 4.XII.50"; AMNH.

\section{Diagnosis}

Head longer than wide. Antennomere 4 elongate. Teeth on labrum blunt. Eyes smaller than in M. iowaensis sp. nov., ca $1 / 6$ of head length. Median emargination of posterior margin of sternum VIII deeper and broader than in M. iowaensis sp. nov.

\section{Redescription}

BoDy. Colour of specimens from pale brown/sandy to brown (Fig. 1A-B). Head and tip of abdomen darker. Body length from tip of head to tip of abdomen 5.5-6.0.

HEAD. Width 1.0-1.1, length 1.0-1.5. Antennomere 1 elongate, widest at tip; antennomeres 2 and 3 elongate; antennomere 4 weakly elongate; antennomeres 5 to 10 gradually becoming strongly transverse; antennomere 11 elongate, $1.5 \times$ as long as antennomere 10. Antennomeres 1 and 2 sparsely pubescent; antennomeres 3 and 4 more densely pubescent, 5 to 11 densely covered with tomentose pubescence. Maxillary palpomere 2 short and slender, with only few setae, maxillary palpomere 3 slightly expanded towards apex with denser setation, maxillary palpomere 4 glossy. Eyes about $1 / 6$ of head length, shifted anteriorly, $1 / 4$ to $1 / 5$ of temple length. 
Thorax. Pronotum width 0.9-1.0, length 1.0-1.1. Elytra width 1.4-1.5, length 1.3-1.4.

LEGS. Two long setae on outer margin of metacoxa. Seta closer to abdomen longer and thicker than seta more distant from abdomen.

AвDOMEN. Sternum VII with apical margin straight. Tergum VIII with rounded posterior margin. Male with sternum VIII with moderately deep and broad median emargination of posterior margin; depth of emargination of ca $1 / 5$ of sternum length; sides of emargination rounded (Fig. 1C); surface right anterior to emargination without setae, while margins with dense setation.

AEDEAGUS. With ventral process in parameral view narrower in middle; lateral plates of internal sac fused to sides of median lobe and indistinctive (Fig. 1D-E).

\section{Occurrence}

The species has previously been recorded from the Canadian provinces of Manitoba, Newfoundland and Labrador, and Ontario and the following US states: Illinois, Indiana, Iowa, Massachusetts, New Jersey and Ohio (A. Newton, unpublished database). New state records include: Missouri, New Hampshire, Pennsylvania and Texas.
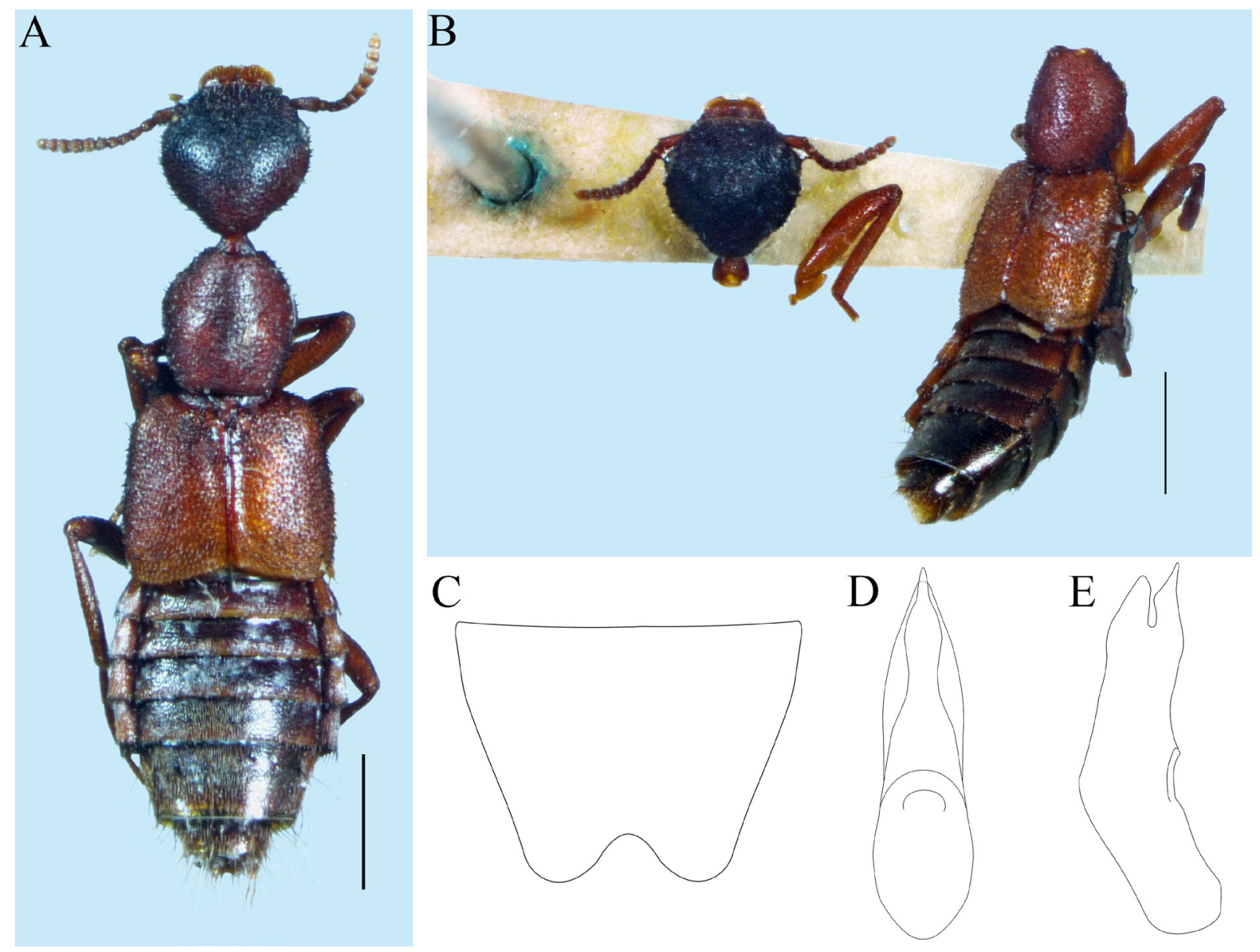

Fig. 1. Morphology of Megastilicus formicarius Casey, 1889. A. Dorsal habitus of paralectotype (NMNH). B. Dorsal habitus of lectotype (NMNH). C. Sternum VIII. D. Aedeagus in parameral view. E. Aedeagus in lateral view. Scale bars $=1 \mathrm{~mm}$. 


\section{Megastilicus iowaensis sp. nov. urn:1sid:zoobank.org:act:9603D57D-FAA2-4DAD-B68F-C91647D98CD0}

Fig. 2

\section{Diagnosis}

Head as long as wide. Antennomere 4 more transverse compared to elongated in Megastilicus formicarius. Teeth on labrum pointed. Eyes larger than in M. formicarius, ca 1/5 of head length. Median emargination of posterior margin of sternum VIII shallower and narrower than in M. formicarius.

\section{Etymology}

The species name 'iowaensis' is derived from the name of the US state Iowa where this species has been collected.

\section{Type material}

\section{Holotype}

USA - $\hat{O}$ with ant [identified as Formica subsericea]; "Iowa City Wickham IV 10? / WICKHAM Collection 1933”; NMNH.

\section{Paratypes}

USA • 1 क; "Iowa City Iowa IV 10 Wickham / WICKHAM Collection 1933"; NMNH • 1 q with ant; "Iowa City Wickham IV-13-?8 / WICKHAM Collection 1933"; NMNH • 1 q with ant; "Iowa City Wickham IV-29-68? / Megastilicus formicarius Csy. / Host ant: Formica subsericea / 9650 / Percy Gardner Bolster Coll’n / M. formicarius Casey 9650 / MCZ ENT 00744565”; MCZ.

\section{Description}

BoDy. Colour of specimens pale brown/sandy (Fig. 2A-B). Head darker. Body length from tip of head to tip of abdomen 6.0.

HEAD. Width 1.0, length 1.1-1.2. Antennomere 1 elongate, widest at tip; antennomeres 2 and 3 elongate; antennomeres 4 to 10 gradually becoming strongly transverse; antennomere 11 elongate, $1.5 \times$ as long as antennomere 10. Antennomeres 1 and 2 sparsely pubescent, antennomeres 3 and 4 more densely pubescent, antennomeres 5 to 11 densely covered with tomentose pubescence. Emargination on anterior margin of labrum shallow. Maxillary palpomere 2 slender and short, with only few setae, maxillary palpomere 3 slightly expanded towards apex with denser setation, maxillary palpomere 4 glossy. Eyes about $1 / 5$ of head length, shifted anteriorly, $1 / 3$ of temple length.

ThORax. Pronotum width 0.9, length 1.0-1.1. Elytra width 1.4-1.5, length 1.3-1.4.

LEGS. Two long setae on outer margin of metacoxa. Seta closer to abdomen shorter and thinner than seta more distant from abdomen.

ABDomen. Tergum VIII with slightly pointed posterior margin. Male with sternum VIII with shallow and broad median emargination of posterior margin; depth of emargination of ca $1 / 7$ of sternum length; sides of emargination rounded (Fig. 2C); surface anterior to emargination without setae, while margins with dense setation.

AEDEAGUS. With ventral process in parameral view widened in middle; lateral plates of internal sac welldeveloped and attached to sides of median lobe (Fig. 2D-E). 


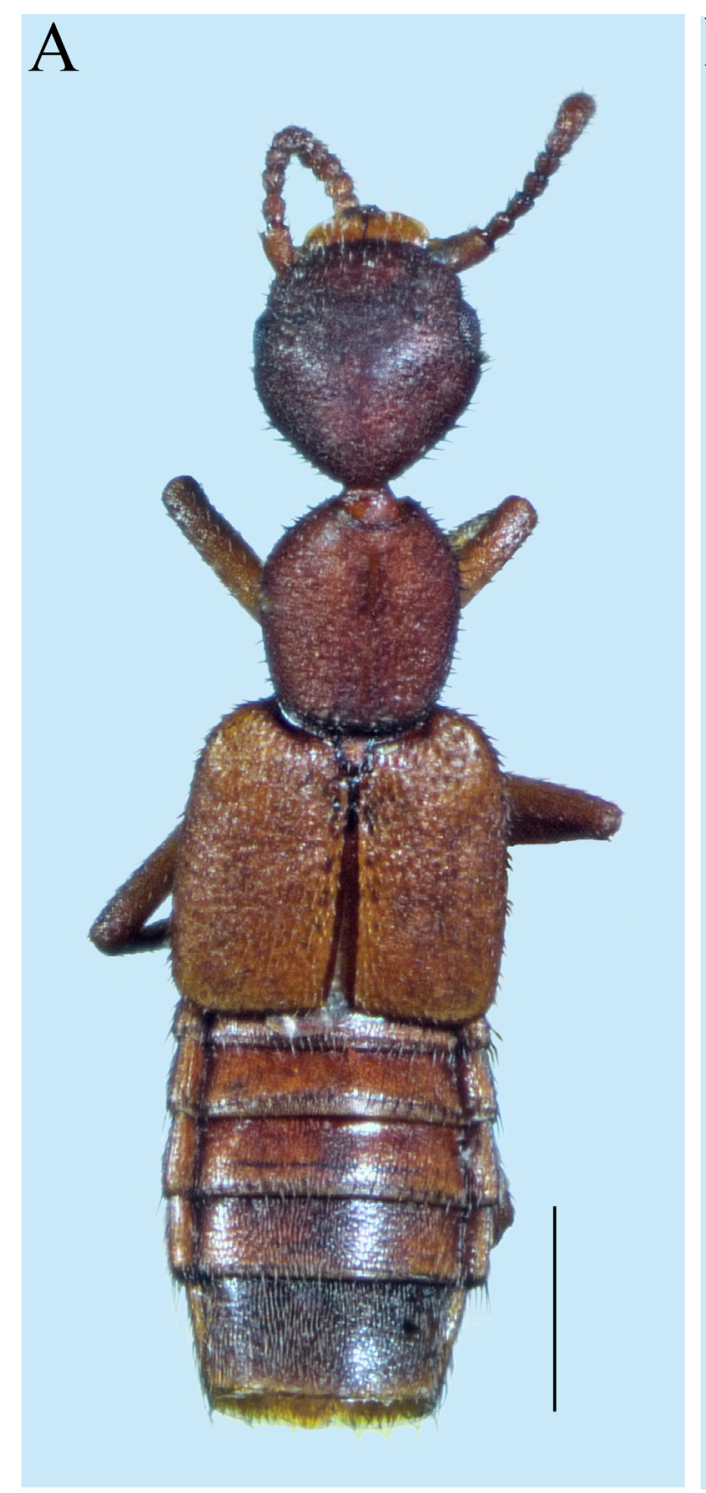

B

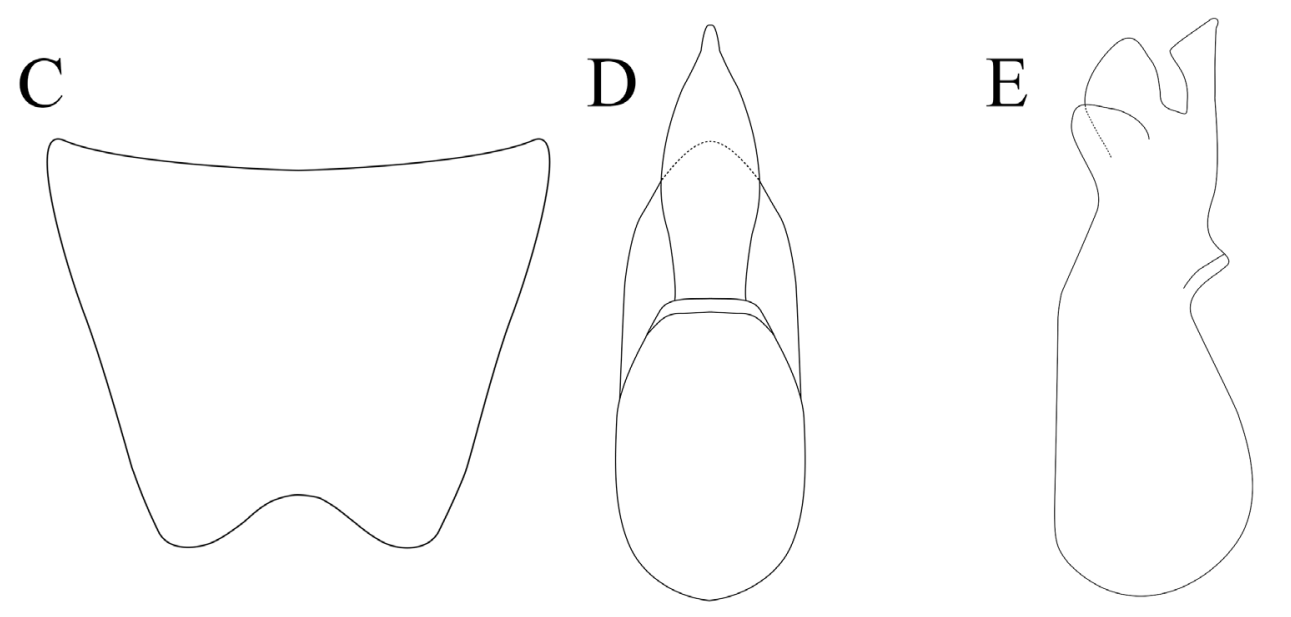

Fig. 2. Morphology of Megastilicus iowaensis sp. nov. A. Dorsal habitus of holotype (NMNH). B. Dorsal habitus of paratype (NMNH). C. Sternum VIII. D. Aedeagus in parameral view. E. Aedeagus in lateral view. Scale bars $=1 \mathrm{~mm}$. 


\section{Occurrence}

The new species has so far only been recorded from Iowa State.

\section{Key to the species of Megastilicus Casey, 1889}

1. Head longer than wide; antennomere 4 elongate; teeth on labrum blunt; eyes about $1 / 6$ of head length, $1 / 4$ to $1 / 5$ of temple length; median emargination of posterior margin of sternum VIII of ca $1 / 5$ of sternum length, ventral process of aedeagus narrower in middle (parameral view); lateral plates of internal sac indistinctive M. formicarius Casey, 1889

- Head as long as wide; antennomere 4 transverse; teeth on labrum pointed; eyes about $1 / 5$ of head length, $1 / 3$ of temple length; median emargination of posterior margin of sternum VIII of ca $1 / 7$ of sternum length; ventral process of aedeagus widened in middle (parameral view); lateral plates of internal sac distinctive

M. iowaensis sp. nov.

\section{Discussion}

Our study revealed a new species in the previously monotypic genus Megastilicus. The new species differs from $M$. formicarius in several general characters as well as the genital structures. Both species occur in Iowa State but are perhaps associated with different ant species. So far, Megastilicus iowaensis sp. nov. was found only with Formica subsericea, while M. formicarius was found with Formica exsectoides and likely Formica ulkei. However, more data are needed to confirm this.

The genus can be assigned to Stilicina based on the following combination of characters: antennae not geniculate; labrum large, almost completely covering mandibles from above; maxillary palpomere 4 glabrous and thin; gular sutures fused; neck narrow, about $1 / 5$ of head width; anterior angles of pronotum obtuse (apex of pronotum with neck-like projection); prosternum not expanded under anterior coxae; protarsomere 4 not bilobed; apical ctenidium on one side of metatibia. We can also state that from the known modifications of beetles adapted to myrmecophily (Parker 2016), Megastilicus presents the following: modifications of the body shape and colouration; compacted protarsal segments; thickening of the antennomeres and their compaction.

Additional state records in the US, except for Texas, are consistent with the general idea of the Midwest and Northeast distribution of the genus (Fig. 3). The specimens from Texas differ slightly from Megastilicus formicarius in colouration, but the examination of only few available specimens did not show enough characters that would justify describing a new species. It is difficult to say anything about the habitat of the Texas specimens because of the lack of data on the label, which only states it was collected in "Сyp Mills Tex". When more specimens become available, it is possible that this is actually yet another species of Megastilicus, but for the time being, we decided to keep it as M. formicarius.

\section{Acknowledgements}

We are grateful to all the curators and managers for access to the collections and all their help. We acknowledge Josh Jenkins Shaw for kindly revising the language of the manuscript. We thank Gregory Courtney for the access to his lab and photo equipment at the Department of Entomology, Iowa State University. Dean Adams is acknowledged for providing DŻ with equipment that made this study possible. We both want to thank Lee Herman for his kindness and inspiring discussions about Paederinae. An anonymous reviewer as well as the editors of the journal are acknowledged for the comments that improved the manuscript. This project has received funding from the European Union's Horizon 2020 research and innovation programme under the Marie Sklodowska-Curie grant agreement No 797823 (postdoctoral fellowship of DŻ) and from the Polish National Science Centre, grant number 2019/35/B/ NZ8/03431. DŻ was additionally funded by the Ernst Mayr Travel Grant in Animal Systematics through the Harvard Museum of Comparative Zoology to visit MCZ and AMNH collections. 


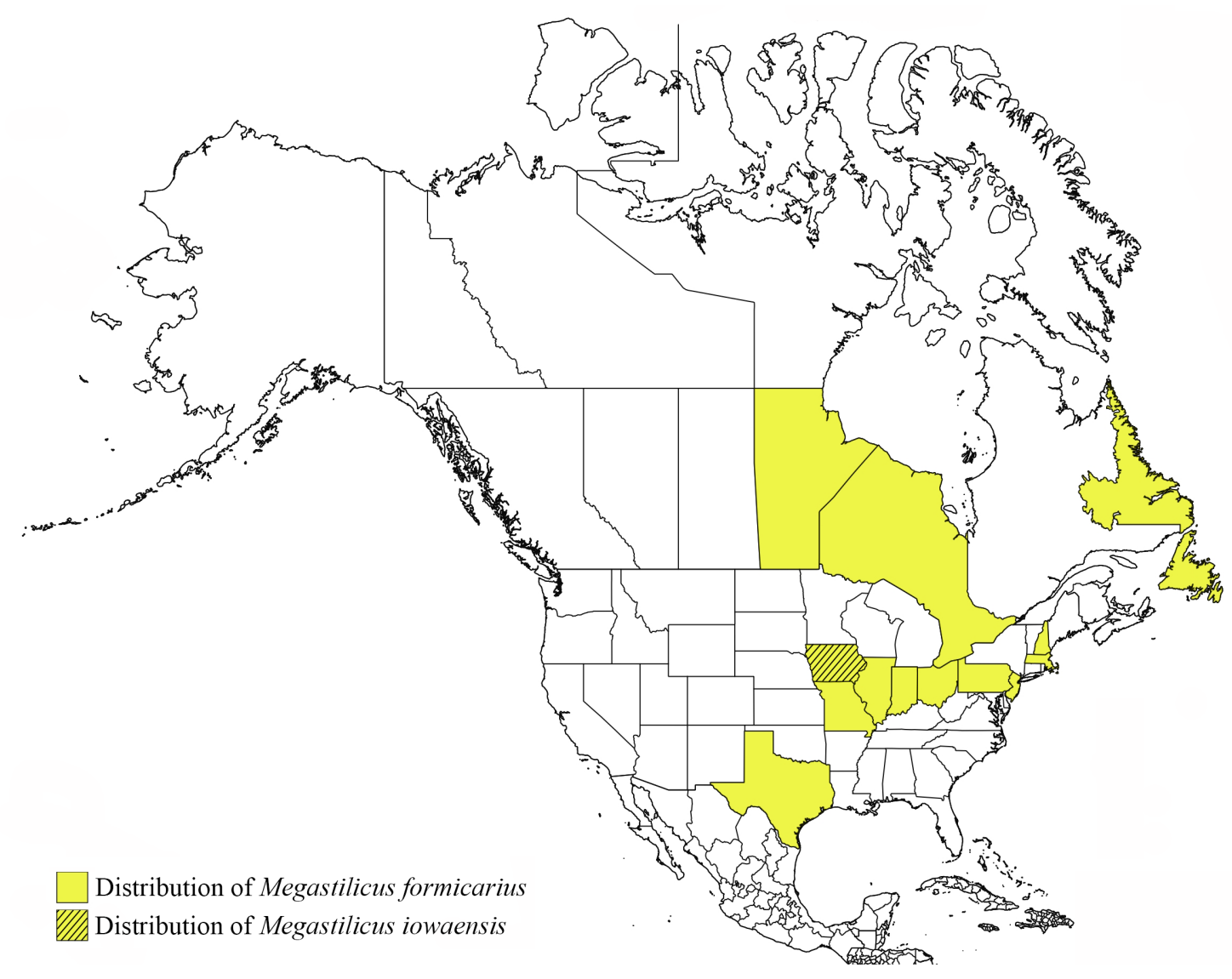

Fig. 3. Distribution of the genus Megastilicus Casey, 1889. Created with SimpleMappr (www.simplemappr.net).

\section{References}

AntWiki. 2017. Key to New England Formica. Available from https://www.antwiki.org/wiki/Key_to_New_England_Formica [accessed 3 Nov. 2021].

Blackwelder R.E. 1939. A generic revision of the staphylinid beetles of the tribe Paederini. Proceedings of the United States National Museum 87: 93-125. https://doi.org/10.5479/si.00963801.87-3069.93

Bogri A., Solodovnikov A., Kypke J.L. \& Żyła D. 2020. Baltic amber members of the extant MicrillusScymbalium lineage of the Paederinae rove beetles (Coleoptera, Staphylinidae) and their systematic and ecological significance. Invertebrate Systematics 34 (5): 451-473. https://doi.org/10.1071/IS19070

Bousquet Y., Bouchard P., Davies A.E. \& Sikes D.S. 2013. Checklist of beetles (Coleoptera) of Canada and Alaska. ZooKeys 360: 1-44. https://doi.org/10.3897/zookeys.360.4742

Casey T.L. 1889. Notes on the Paederini. Entomologica Americana 5: 182-184.

Casey T.L. 1905. A revision of the American Paederini. Vol. 15, No. 2. Academy of Science of St. Louis, Saint Louis. https://doi.org/10.5962/bhl.title.9845

Herman Jr L.H. 1970. The ecology, phylogeny, and taxonomy of Stilicolina (Coleoptera, Staphylinidae, Paederinae). American Museum Novitates 2412: 1-26.

Holmquist A.M. 1928a. Notes on the life-history and habits of the mound-building ant, Formica ulkei Emery. Ecology 9: 70-87. https://doi.org/10.2307/1929544 
Holmquist A.M. 1928b. Studies in arthropod hibernation. II. The hibernation of the ant, Formica ulkei Emery. Physiological Zoology 1: 325-57. https://doi.org/10.1086/physzool.1.3.30151051

Leng C.W. \& Wickham H.F. 1920. Catalogue of the Coleoptera of America, North of Mexico. JD Sherman Jr., Mount Vernon. https://doi.org/10.5962/bhl.title.8777

Moore I. \& Legner E.F. 1974. Keys to the genera of the Staphylinidae of America north of Mexico exclusive of the Aleocharinae (Coleoptera: Staphylinidae). Hilgardia 42 (16): 548-563.

https://doi.org/10.3733/hilg.v42n16p548

Moore I. \& Legner E.F. 1979. An Illustrated Guide to the Genera of the Staphylinidae of America North of Mexico Exclusive of the Aleocharinae (Coleoptera). University of California Division of Agricultural Sciences Priced Publication, Berkeley.

Newton Jr A.F., Thayer M.K., Ashe J.S. \& Chandler D.S. 2000. 22. Staphylinidae Latreille, 1802. In: Arnett Jr R.H. \& Thomas M.C. (eds) American Beetles: Archostemata, Myxophaga, Adephaga, Polyphaga: Staphyliniformia Vol. 1: 272-418. CRC press., Boca Raton.

Park O. 1929. Ecological observations upon the myrmecocoles of Formica ulkei, especially Leptinus testaceus Mueller. Psyche 36: 195-215. https://doi.org/10.1155/1929/58409

Park O. 1935. Beetles associated with the mound-building ant, Formica ulkei Emery. Psyche 42: 216-231. https://doi.org/10.1155/1935/46146

Parker J. 2016. Myrmecophily in beetles (Coleoptera): evolutionary patterns and biological mechanisms. Myrmecological News 22: 65-108.

Shorthouse D.P. 2010. SimpleMappr, an online tool to produce publication-quality point maps. Available from http://www.simplemappr.net [accessed 11 May 2021].

Wickham H.F. 1900. On Coleoptera found with ants. Fifth paper. Psyche 9: 3-5. https://doi.org/10.1155/1900/185328

Wickham H.F. 1911. A list of the Coleoptera of Iowa. Bulletin of the State University of Iowa (new series no. 35) 6 (2): 1-40.

Manuscript received: 19 May 2021

Manuscript accepted: 19 October 2021

Published on: 22 November 2021

Topic editor: Nesrine Akkari

Section editor: Max Barclay

Desk editor: Radka Rosenbaumová

Printed versions of all papers are also deposited in the libraries of the institutes that are members of the EJT consortium: Muséum national d'histoire naturelle, Paris, France; Meise Botanic Garden, Belgium; Royal Museum for Central Africa, Tervuren, Belgium; Royal Belgian Institute of Natural Sciences, Brussels, Belgium; Natural History Museum of Denmark, Copenhagen, Denmark; Naturalis Biodiversity Center, Leiden, the Netherlands; Museo Nacional de Ciencias Naturales-CSIC, Madrid, Spain; Real Jardín Botánico de Madrid CSIC, Spain; Zoological Research Museum Alexander Koenig, Bonn, Germany; National Museum, Prague, Czech Republic. 